\title{
Thermophysical Properties of Cement Mortar Containing Waste Glass Powder
}

\author{
Oumaima Nasry $1, * \mathbb{1}$, Abderrahim Samaouali ${ }^{1, *}$, Sara Belarouf ${ }^{1}$, Abdelkrim Moufakkir ${ }^{1}$, \\ Hanane Sghiouri El Idrissi ${ }^{1}$, Houda Soulami ${ }^{1}$, Younes El Rhaffari ${ }^{2}$, Mohamed Hraita ${ }^{3}$, Saïf Ed Dîn Fertahi ${ }^{1}$ \\ and Adil Hafidi-Alaoui ${ }^{4}$
}

check for updates

Citation: Nasry, O.; Samaouali, A.; Belarouf, S.; Moufakkir, A.; Sghiouri El Idrissi, H.; Soulami, H.; El Rhaffari, Y.; Hraita, M.; Fertahi, S.E.D.; Hafidi-Alaoui, A. Thermophysical Properties of Cement Mortar Containing Waste Glass Powder. Crystals 2021, 11, 488. https:// doi.org/10.3390/cryst11050488

Academic Editor:

Per-Lennart Larsson

Received: 22 March 2021

Accepted: 21 April 2021

Published: 27 April 2021

Publisher's Note: MDPI stays neutral with regard to jurisdictional claims in published maps and institutional affiliations.

Copyright: (c) 2021 by the authors. Licensee MDPI, Basel, Switzerland. This article is an open access article distributed under the terms and conditions of the Creative Commons Attribution (CC BY) license (https:// creativecommons.org/licenses/by/ $4.0 /)$.
1 Team Thermodynamic-Energy, Energy Research Center, Department of Physics, Faculty of Sciences, Mohammed V University, B.P. 1014, in Rabat 10090, Morocco; belarouf.sarah@gmail.com (S.B.); ab.moufakkir@gmail.com (A.M.); hananesghiourielidrissi@gmail.com (H.S.E.I.); huda.soulami@gmail.com (H.S.); fertahi.sayfdin@gmail.com (S.E.D.F.)

2 High school of technology of sale, Mohammed V University of Rabat, avenue Le prince Heritier, B.P. 227, in Sale 11000, Morocco; ayounes1@hotmail.com

3 Higher Normal School of Rabat (E.N.S. Rabat) Thermodynamics-energy Team, Energy Research Center Faculty of sciences, Mohammed V University, B.P. 1014, in Rabat 10090, Morocco; simo.hraita@yahoo.fr

4 Mechanical Laboratory and Civil Engineering, Faculty of sciences and technology, Abdelmalek Essaadi University, B.P. 416, in Tangier 90000, Morocco; pr_alaoui@yahoo.fr

* Correspondence: oumaima_nasry@um5.ac.ma (O.N.); abderrahimsamaouali@yahoo.fr or a.samaouali@um5r.ac.ma (A.S.)

Abstract: This study aims to provide a thermophysical characterization of a new economical and green mortar. This material is characterized by partially replacing the cement with recycled soda lime glass. The cement was partially substituted (10,20,30, 40, 50 and $60 \%$ in weight) by glass powder with a water/cement ratio of 0.4 . The glass powder and four of the seven samples were analyzed using a scanning electron microscope (SEM). The thermophysical properties, such as thermal conductivity and volumetric specific heat, were experimentally measured in both dry and wet (water saturated) states. These properties were determined as a function of the glass powder percentage by using a CT-Meter at different temperatures $\left(20^{\circ} \mathrm{C}, 30^{\circ} \mathrm{C}, 40^{\circ} \mathrm{C}\right.$ and $\left.50{ }^{\circ} \mathrm{C}\right)$ in a temperature-controlled box. The results show that the thermophysical parameters decreased linearly when $60 \%$ glass powder was added to cement mortar: $37 \%$ for thermal conductivity, $18 \%$ for volumetric specific heat and $22 \%$ for thermal diffusivity. The density of the mortar also decreased by about $11 \%$ in dry state and $5 \%$ in wet state. The use of waste glass powder as a cement replacement affects the thermophysical properties of cement mortar due to its porosity as compared with the control mortar. The results indicate that thermal conductivity and volumetric specific heat increases with temperature increase and/or the substitution rate decrease. Therefore, the addition of waste glass powder can significantly affect the thermophysical properties of ordinary cement mortar.

Keywords: soda lime waste glass; composite mortar; thermal conductivity; volumetric specific heat; effect of temperature

\section{Introduction}

The building construction industry is currently experiencing remarkable growth in the manufacturing of building materials. Concrete is produced with different compositions of ingredients based on the strength and performance requirements of the structure. The most commonly-used concrete is Normal Strength Concrete (NSC). The primary components of concrete are the binder or cement, fine aggregates, coarse aggregates, and water. In order to attain high strength or high performance standards, certain secondary components such as fly ash, ground granulated blast furnace slag (slag), silica fume, and superplasticizers are added to the design mix [1]. 
Cement mortar contains cement as a binder, sand as fine aggregate, water, and in some cases admixture. Next to concrete, mortar is also in high demand, as it ensures the bonding of masonry walls and provides thermal and phonic insulation. Portland cement (hydraulic binder) is the raw material used in manufacturing mortar. However, this material consumes large quantities of natural resources (limestone and clay) and generates a great amount of carbon dioxide during the preparation of clinker. Hence, the challenge of the entire industry is to reduce the consumption of cement by developing new ecological materials that are more efficient in mechanical and thermal terms.

Recently, the use of waste or by-products to produce sustainable building materials has been the subject of many studies due to their economic, environmental, and technical advantages. Replacing cement and/or sand with sustainable materials produces a sustainable cement mortar or even concrete [2-7]. Over the past two decades, recycling glass waste as a component of building material has been the subject of several studies [8-19].

These studies have shown that glass powders are used in manufacturing mortar and concrete because of the chemical and physical compatibility of sand. Jani and Hogland [8] have shown that the pozzolanic properties of glass increase with the decrease in the size of glass particles. Furthermore, the fine particles of glass favor a rapid pozzolanic reaction compared to slower alkali silica reaction (ASR) [20-23]. The chemical composition of glass also plays a very important role in the development of the pozzolanic reaction, the decrease in the rate of RAS reactions and, subsequently, influences the physical and mechanical properties of glass waste materials [24]. It follows that the choice of the type of glass must be made according to the amount of glass formers and glass stabilizers, which must be high compared to that of glass modifiers.

Regarding the mechanical properties of concrete and mortar based on powdered glass waste, it has recently been shown that cement mortar made with $60 \%$ recycled green glass powder has bigger pores due to the dilution. Chemical shrinkage and heat assessment show that the high glass powder replacement of cement paste increases the hydration reaction rate. Compressive strength and dynamic Young's and shear moduli values decrease with increasing glass powder content especially for mortar made with $60 \%$ glass powder. Significant compressive strength is gained between 7 and 90 days for mortar with glass powder, especially with a $60 \%$ replacement showing pozzolanic reaction taking place during this period [10].

Du and Tan [12] evaluated properties of high-volume glass powder concrete (up to $60 \%$ ). Beyond a replacement of $30 \%$, calcium hydroxide became insufficient for the pozzolanic reaction of glass powder. The amount of calcium hydroxide decreased significantly at 45 and $60 \%$, which shows that all the calcium hydroxide formed was consumed during the pozzolanic reaction. However, the composite concrete retained distinct resistance against water and chloride ingress.

In another study where mixtures contained 30\% GP, the concrete strength at 404 days exceeded the target strength and reached up to $55 \mathrm{MPa}$ [25].

The results from studies presented above reinforce the use of glass as a supplement in building materials. However, several researchers are interested in the studying thermal properties of concrete and/or mortar [26-28]. The thermal properties of building materials, including thermal conductivity, volumetric specific heat, and thermal diffusivity have a substantial effect on the energy consumption of buildings. The thermal properties of mortar and concrete can play an important role in the sustainability of buildings [2].

Experiments have shown that cement incorporated with $20 \%$ glass powder has lower thermal conductivity and specific heat than that of ordinary cement [20]. It should be noted that all thermal properties must be considered to prepare favorable living conditions. However, in most available studies, only the thermal conductivity and the specific heat of the material were evaluated. Until now, the study of the thermal properties of mortar with high contents of glass powder has not been carried out. For that, the main objective of this research is to conduct a detailed experimental study on the thermo-physical parameter variations (thermal conductivity, specific heat, thermal diffusivity, and thermal effusivity) 
of the mortar as a function of the glass powder content ( 0 to $60 \%$ ) in both dry and saturated states. The variation of these different parameters as a function of temperature was also considered. Physicochemical characterizations based on scanning electron microscopy and EDX analysis were made.

\section{Materials and Methods}

\subsection{Materials}

Glass bottles and recycled soda lime were collected from municipal landfills. They were then washed, crushed manually, and then finely crushed until the desired powder was obtained (Figure 1).
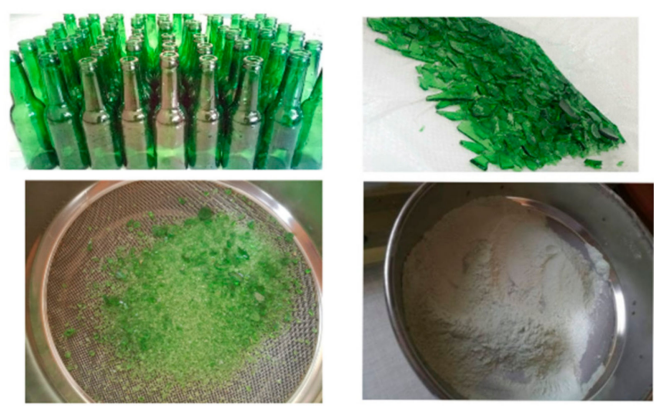

Figure 1. Glass powder preparation.

The Portland cement used is CPJ 45 , containing a minimum clinker ratio of $65 \%$, with the rest being made up of additions (fly ash and pozzolans).

This cement type is often appropriate for reinforced concrete, as well as for massive structures that require a moderate temperature rise. The crushing sand, coming from the Rabat-Sale region, was washed and then dried at $105^{\circ} \mathrm{C}$ for $24 \mathrm{~h}$. The particle size analysis of the two materials used (sand and glass powder) complies with standard NF P-18-560. Figure 2 represents the particle size analysis of the different materials used according to the NF P-18-560 standard.

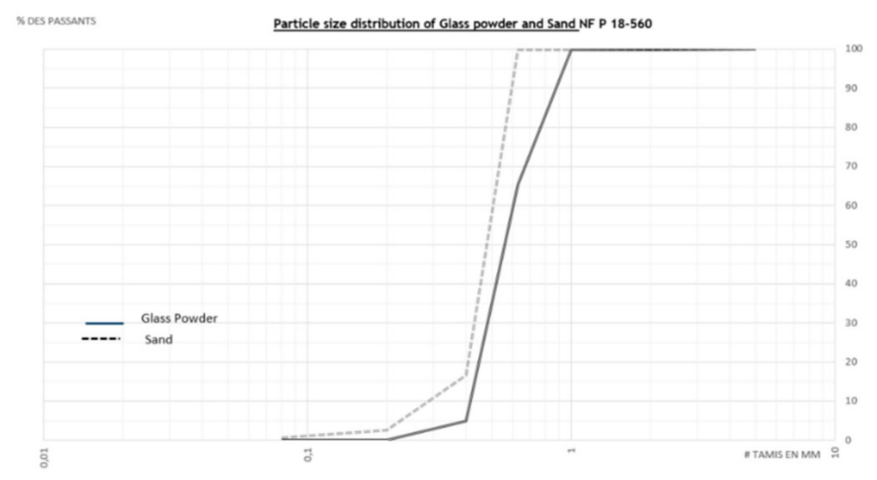

Figure 2. Particle size distribution of glass powder and sand.

\subsection{Samples Preparation}

The samples were prepared in $40 \mathrm{~mm} \times 70 \mathrm{~mm} \times 90 \mathrm{~mm}$ containers. The cement was replaced by glass powder in different mass proportions: $10 \%, 20 \%, 30 \%, 40 \%, 50 \%$ and $60 \%$ (Figure 3). The control sample named MGP0 consists only of Portland cement CPJ45, sand, and mixing water.

The mortar samples studied were prepared with a first water/cement (W/C) ratio of 0.40 and a second Cement/Sand (C/S) ratio of 0.33.

The samples were removed from the molds and soaked in a water tank at $20 \pm 1{ }^{\circ} \mathrm{C}$ for 28 days. Then, the samples were cured in a room conditioned at $20 \pm 1^{\circ} \mathrm{C}$ for 91 days. After 91 days, each sample mortar's dry state was obtained after drying the sample for 
$24 \mathrm{~h}$ in a cooker at $60^{\circ} \mathrm{C}$, while the saturated state was reached after soaking the sample in a tank of water for $48 \mathrm{~h}$ to ensure that the saturation point has been reached.

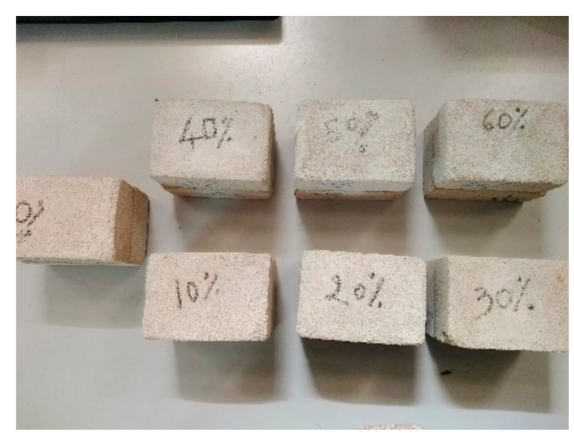

Figure 3. Control mortar samples, substituted at different ratios of glass powder.

The samples' thermal properties were measured at the age of 91 days in both the dry and saturated state as a function of the temperature $\left(20^{\circ} \mathrm{C}, 30^{\circ} \mathrm{C}, 40^{\circ} \mathrm{C}\right.$ and $\left.50{ }^{\circ} \mathrm{C}\right)$.

\subsection{Methods}

The morphology of the samples was verified with a scanning electron microscope JEOL IT 100 type MEOL. In order to get the size of the particle down to four nm as a minimum, a thin layer of gold was used to make the surface more conducive. In order to determine the atomic composition of the samples used in this study, the scanning electron microscope was combined with an energy dispersive spectrometer, which also allows a microanalysis of the used samples in different states: powder or solid.

The thermal properties of the samples were measured using a "CT Meter" device (standard) delivered by the Modern Society of Electronic Studies. This device (CT Meter) measures both the thermal conductivity $(\mathrm{W} /(\mathrm{mK}))$ and the specific heat $\left(\mathrm{KJ} / \mathrm{m}^{3} \mathrm{~K}\right)$ of solid materials [18]. It is equipped with specific sonde for solid materials, a glove box and an interface that couples the editing with a computer to display and process the measured numerical values. The ring sonde is $60 \mathrm{~mm}$ in width, $90 \mathrm{~mm}$ in length and $0.2 \mathrm{~mm}$ in thickness and contains a ring $10 \mathrm{~mm}$ in radius. The sonde was connected to the appliance (CT meter) via a plug (Figure 4). Then, it was inserted between two samples of the same size and shape so that it swept the sample in volume. The operator started the measurement by pressing the MEASURE button. From here, the cycle proceeded automatically, and at the end of the programmed measurement time, the display transmitted the results. Each measure is the average of three measures. Standard measurement uncertainty is 5\%. The equipment used was developed by the CSTB (Technical and Scientific Center for Building) and it complies with the ASTM D5930-97 and AAC 11-3 RILEM recommendations [18].

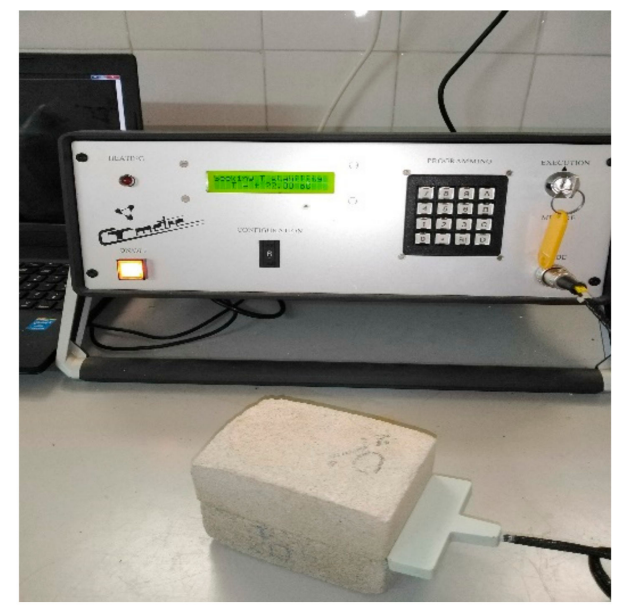

Figure 4. CT METER. 
The thermo-physical properties were determined at different temperatures using a hermetic glove box. It consists of a commercial freezer with a volume of 400 liters, internal dimensions of $120 \mathrm{~cm}$ length, $48 \mathrm{~cm}$ wideness and $72 \mathrm{~cm}$ height. The lid is made of transparent Plexiglas with a thickness of $20 \mathrm{~mm}$. Inside the freezer, two ventilators are driven by 11 watt mini motors to agitate the air and homogenize its temperature. Depending on the desired heating power, one or two heating elements can be switched on at the same time. A contact thermometer controlled by a temperature controller is placed inside the box to keep the temperature stable. The measurement uncertainty of the thermo-regulated glove box is $\pm 1^{\circ} \mathrm{C}$.

The thermal diffusivity (a) was estimated by the following equation:

$$
\mathrm{a}=\lambda / \rho \mathrm{c},
$$

with a: thermal diffusivity, $\lambda$ : thermal conductivity and $\rho c$ : volumetric specific heat.

\section{Results and Discussions}

\subsection{Scanning Electron Microscopy (SEM) and Microanalysis by (EDX)}

The SEM micrographs and the EDX analysis of the glass powder and the Portland cement samples were analyzed. In Figure $5 \mathrm{a}$, the micrograph of the glass powder shows a sharp and varied smooth morphology, with a grain size ranging from 58 to 290 micrometer. However, as observed in Figure 5b, the Portland cement was constituted of finer regular spherical objects in the range of one micrometer. The results of the EDX microanalysis, presented in Table 1, show that the glass powder consists mainly of oxygen and silicon. We also observed a low content of calcium, carbon, sodium, and magnesium. However, cement is constituted by tricalcium silicate $\left(\mathrm{Ca}_{3} \mathrm{SiO}_{5}\right)$, dicalcium silicate $\left(\mathrm{Ca}_{2} \mathrm{SiO}_{4}\right)$, tricalcium aluminate $\left(\mathrm{Ca}_{3} \mathrm{Al}_{2} \mathrm{O}_{5}\right)$, and calcium aluminoferrite $\left(\mathrm{Ca}_{4} \mathrm{AlnFe} \mathrm{F}_{2}-\mathrm{nO}_{7}\right)$. The formula of these minerals can be broken down into basic calcium, silicon, aluminum, and iron oxides, with a strong dominance in calcium (the main component of limestone, which represents about $80 \%$ of raw materials in the Portland cement).

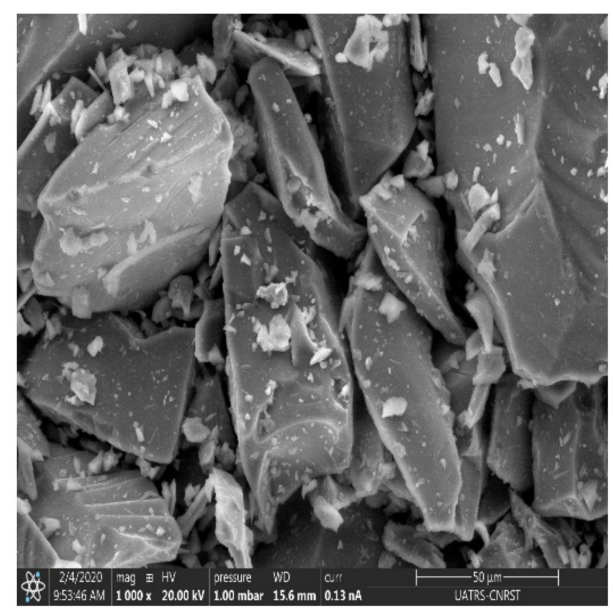

(a)

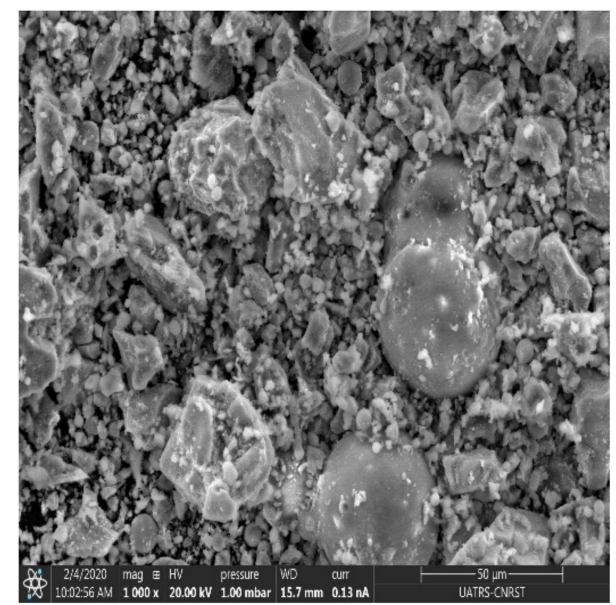

(b)

Figure 5. Scanning electron microscopy of: (a) Glass Powder; (b) Cement.

The microstructures of the mixtures of $0 \%, 10 \%$, and $50 \%$ glass powder were also observed at their dry state using the SEM (Figure 6). The results of the EDX microanalysis are presented in Table 2. The chemical composition of the glass powder makes this material competitive as a pozzolanic material [24]. Thus, the pozzolanic reaction could densify the dough, thanks to the new C-S-H bonds. A weaker interaction of the Ca and Si elements of the alumina reveals that mixing with the glass powder will decrease the amount of portlandite and increase the amount of C-S-H. Figure 6a shows a dense structure of control mortar. The mixture with $10 \%$ of GP shows formations of gel C-S-H and secondary 
hydration due to the pozzolanic characterization, as one can see in Figure 6b. However, this densification of the microstructure was not evident at $50 \%$ of the GPs Figure $6 \mathrm{c}$. The difference in the pore size distribution can be observed for different substituents of the glass powder. We can state that the use of glass powder in the mortar leads to modifications of the pore size. According to Liu, Xie and Wang [29], the quantity of capillary pores decreases, while the quantity of the general porosity increases. This is due to the small size of the glass particles.

Table 1. Chemical composition of GP and Cement obtained from the EDX analysis.

\begin{tabular}{ccc}
\hline Formula & Glass powder (\%atom) & Cement (\%atom) \\
\hline $\mathrm{C}$ & 12.68 & 20.29 \\
$\mathrm{O}$ & 55.4 & 55.99 \\
$\mathrm{Na}$ & 7.07 & 0.20 \\
$\mathrm{Mg}$ & 0.17 & 0.47 \\
$\mathrm{Al}$ & 0.50 & 1.43 \\
$\mathrm{Si}$ & 20.69 & 3.93 \\
$\mathrm{Ca}$ & 3.59 & 15.73 \\
$\mathrm{~S}$ & - & 0.89 \\
$\mathrm{~K}$ & - & 0.53 \\
$\mathrm{Ti}$ & - & 0.05 \\
$\mathrm{Fe}$ & - & 0.47 \\
$\mathrm{Tot}$ & 100.00 & 100.00 \\
\hline
\end{tabular}

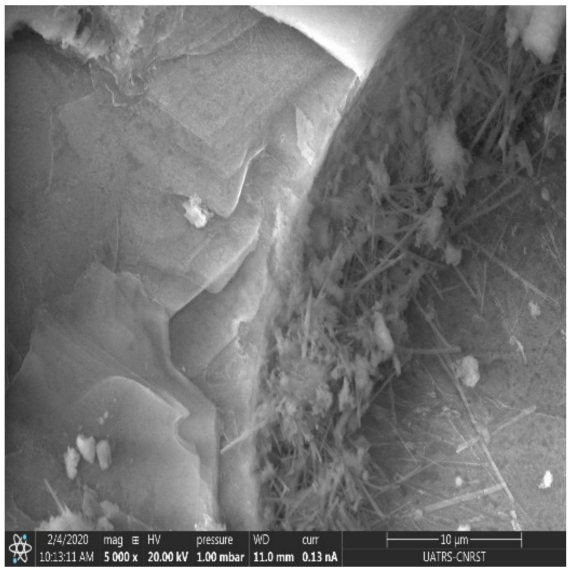

(a)

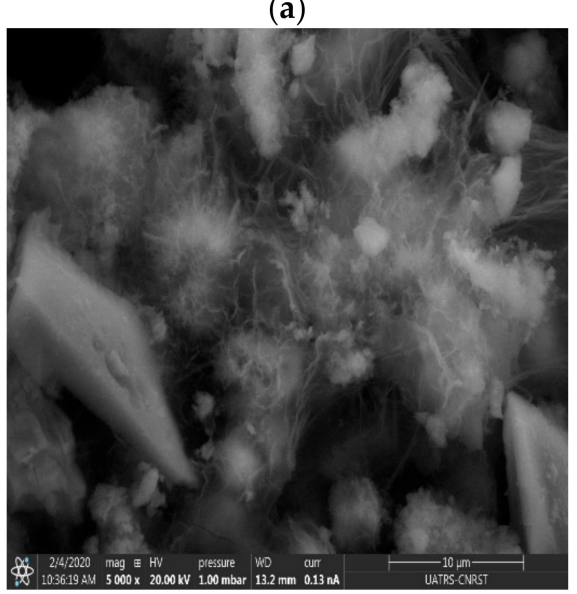

(c)

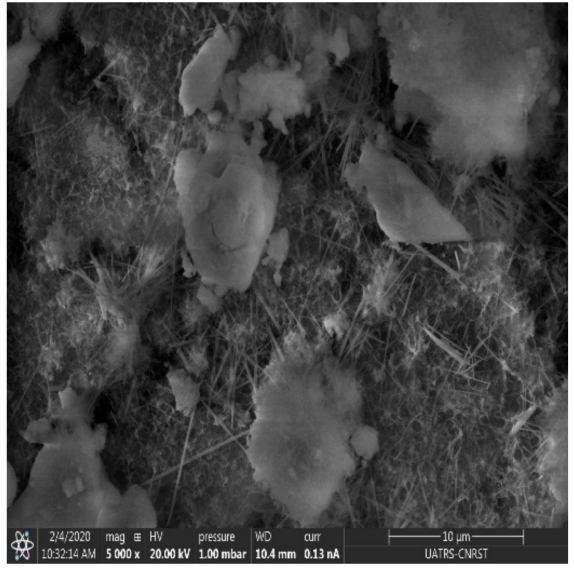

(b)

Figure 6. Scanning electron microscopy of: (a) Control mortar; (b) Mortar glass powder (10\%); (c) Mortar glass powder (50\%). 
Table 2. Chemical composition of (a) Control mortar; (b) Mortar glass powder (10\%); (c) Mortar glass powder (50\%) obtained from the EDX analysis.

\begin{tabular}{cccc}
\hline Formula & (a) \%atom & (b) \%atom & (c) \%atom \\
\hline $\mathrm{C}$ & 9.32 & 10.07 & 8.71 \\
$\mathrm{O}$ & 65.95 & 66.84 & 65.43 \\
$\mathrm{Na}$ & 0.15 & 0.33 & 1.45 \\
$\mathrm{Mg}$ & 0.51 & 0.45 & 0.42 \\
$\mathrm{Al}$ & 1.11 & 1.10 & 1.23 \\
$\mathrm{Si}$ & 7.47 & 7.88 & 10.49 \\
$\mathrm{Ca}$ & 14.34 & 12.31 & 11.38 \\
$\mathrm{~S}$ & 0.41 & 0.49 & 0.45 \\
$\mathrm{~K}$ & 0.22 & 0.16 & 0.13 \\
$\mathrm{Fe}$ & 0.51 & 0.37 & 0.30 \\
$\mathrm{Tot}$ & 100.00 & 100.00 & 100.00 \\
\hline
\end{tabular}

\subsection{Thermo-Physical Properties}

\subsubsection{Relationship between Density and Thermal Conductivity}

The density of the mortars' glass powder (MGP) was measured at $20^{\circ} \mathrm{C}$ for both dry and water saturated states. Each measure is the average of three measures. The diameter and height of each sample were measured with a digital caliper with a precision of $0.01 \mathrm{~mm}$, while the mass was determined using a $0.005 \mathrm{~g}$ precision scale.

The results (Table 3) show that this density decreases in the dry state by a maximal percentage (about $11.16 \%$ ) when the glass powder percentage is increased up to $60 \%$. In the saturated state, the density decreases from 2.1 to $1.98 \mathrm{~g} / \mathrm{cm}^{3}$ which corresponds to a variation of only $5.71 \%$. This could be explained by the low absorption of water in the glass. The increase in the volumic mass of the samples in the saturated state compared to the dry state could be explained by water occupating the empty pores, which subsequently induces an increase of the density of the mortars.

Table 3. Measured densities of the mortar glass powder (MGP) samples in the dry and saturated states.

\begin{tabular}{cccccccc}
\hline $\begin{array}{c}\text { MGP } \\
(\mathbf{\%})\end{array}$ & $\mathbf{0}$ & $\mathbf{1 0}$ & $\mathbf{2 0}$ & $\mathbf{3 0}$ & $\mathbf{4 0}$ & $\mathbf{5 0}$ & $\mathbf{6 0}$ \\
\hline Wet & 2.1 & 2.07 & 2.05 & 2.03 & 2.01 & 2.00 & 1.98 \\
\hline Dry & 2.06 & 1.97 & 1.95 & 1.94 & 1.90 & 1.86 & 1.83 \\
\hline
\end{tabular}

As shown in Figure 7, it can be noticed that the variation in thermal conductivity of the mortars incorporated by the glass powder linearly increases as their densities increase. This indicates the existence of a correlation between these thermophysical parameters. From the results shown in Figure 7, it is possible to establish a linear, empirical law between thermal conductivity and density in the case of mortars with different glass powder substitution rates. This result is similar to that obtained by [30], in which the thermal conductivity was strictly linked to the density of concrete. The increase in the substitution rate of the glass powder leads to an increase in the volume of the pores, which causes a lower density and consequently leads to a decrease of the thermal conductivity of the mortars. 


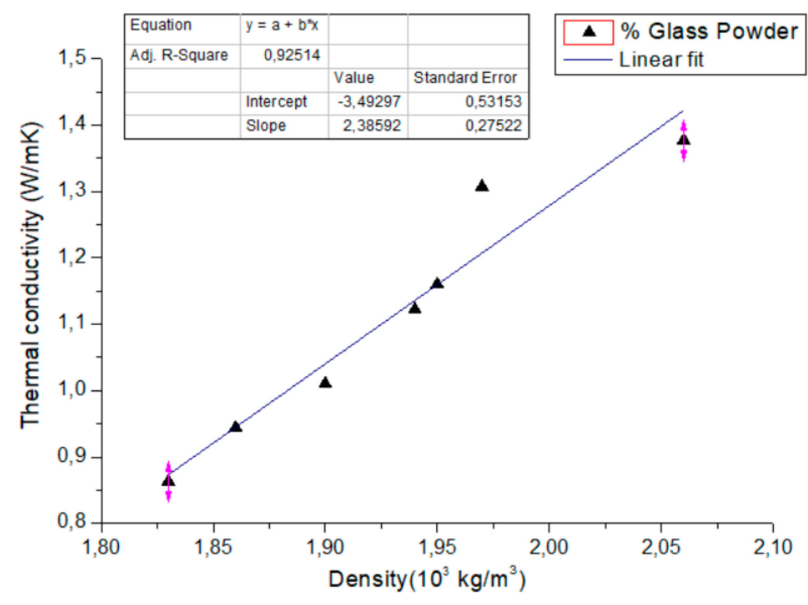

Figure 7. Variation of the thermal conductivity as a function of the bulk density.

\subsubsection{Effect of Glass Powder Content on Thermal Conductivity and Specific Heat}

Figure 8a illustrates the variation of the thermal conductivity as a function of the water content of the mortar at different percentages of glass powder. This curve clearly shows that the thermal conductivity and the specific heat decrease with the addition of glass powder. This thermal conductivity decreases up to $0.86 \mathrm{~W} /(\mathrm{mK})$ when the percentage of glass powder reaches $60 \%$, which corresponds to a reduction of $37.32 \%$ when compared to the control mortar. These results are in agreement with those of [31], who showed that the thermal conductivity of the cement paste decreases with the addition of glass powder and for glass substitution rates lower than $20 \%$. We attribute this decrease in thermal conductivity based on the substitution rate to the fact that the glass is amorphous and non-conductive. The presence of air $(0.03 \mathrm{~W} /(\mathrm{mK}))$ in the porous material can also significantly influence thermal conductivity.

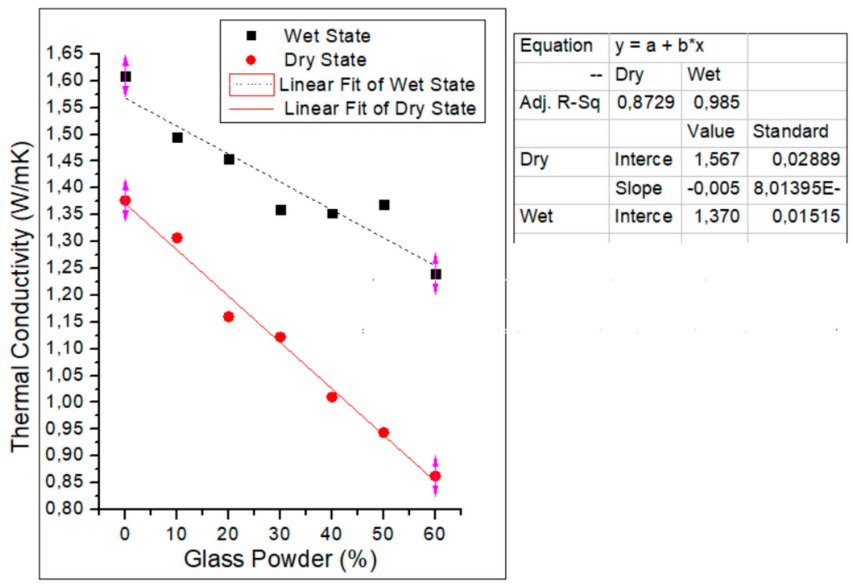

(a)

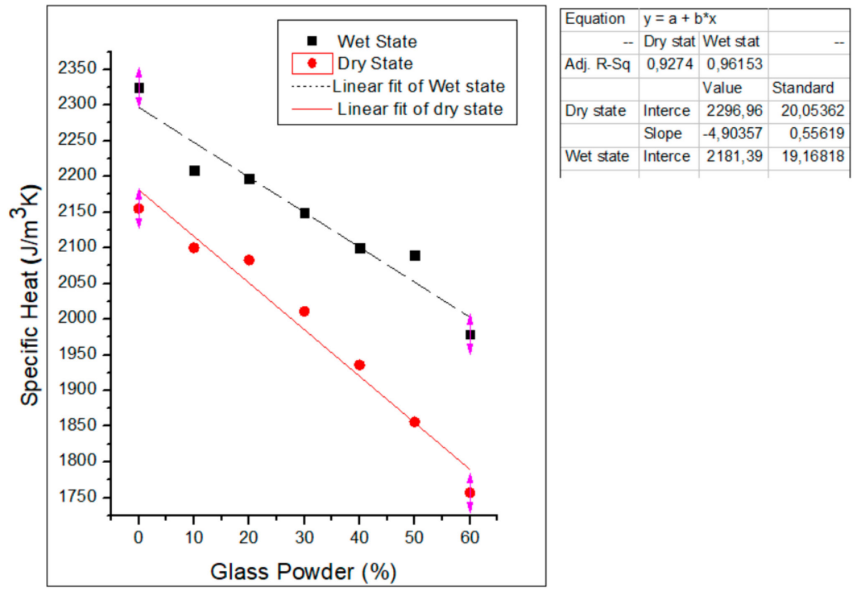

(b)

Figure 8. Variation of the measured mortars thermal conductivity (a) and specific heat (b) at dry and wet states as a function of the glass powder content.

However, samples saturated with water have a higher thermal conductivity. This can be explained by an increase in the pores accessible to water, which has a thermal conductivity $(0.59 \mathrm{~W} /(\mathrm{mK}))$ greater than that of air at room temperature.

Measurements of the specific heat of the mortars were carried out for different substitution rates for glass powder in dry and saturated states using a CT meter machine. These results (Figure $8 b$ ) show that in the dry state, the specific heat of mortars decreases from 2155 to $1757 \mathrm{KJ} / \mathrm{m}^{3} \mathrm{~K}$ when the glass substitution rate varies from 0 to $60 \%$, i.e., a variation 
of $18.46 \%$. This result is in complete agreement with the work of Pan et al. [20]. The resulting material is characterized by new thermo-physical properties. These properties are attributed to exothermic hydration reactions, which are activated when the binder is mixed with water. The localized heat released will reorganize the water molecules in the microstructure of the skeleton. Unlike thermal conductivity, specific heat does not depend on how its different constituents are arranged but on the volume fraction of its components. The small decrease in the specific heat of the mortars as a function of the glass powder percentages is explained by the low specific thermal value of the glass $\left(913 \mathrm{KJ} / \mathrm{m}^{3} \mathrm{~K}\right)$ and that of the air $\left(1005 \mathrm{KJ} / \mathrm{m}^{3} \mathrm{~K}\right)$ which are located in pores.

In the saturated state, the specific heat decreases from 2325 to $1979 \mathrm{KJ} / \mathrm{m}^{3} \mathrm{~K}$, a variation of $14.88 \%$. The increase in specific heat from dry to saturated state is due to the increase in the amount of water absorbed in the pores and, therefore, to the replacement of air, which has low specific heat, by water $\left(4181.3 \mathrm{KJ} / \mathrm{m}^{3} \mathrm{~K}\right)$.

\subsubsection{Effect of Glass Powder Content on Thermal Diffusivity}

Thermal diffusivity is the quotient of thermal conductivity over specific heat. The results represented in Figure 9 have been deduced from the Equation (1).

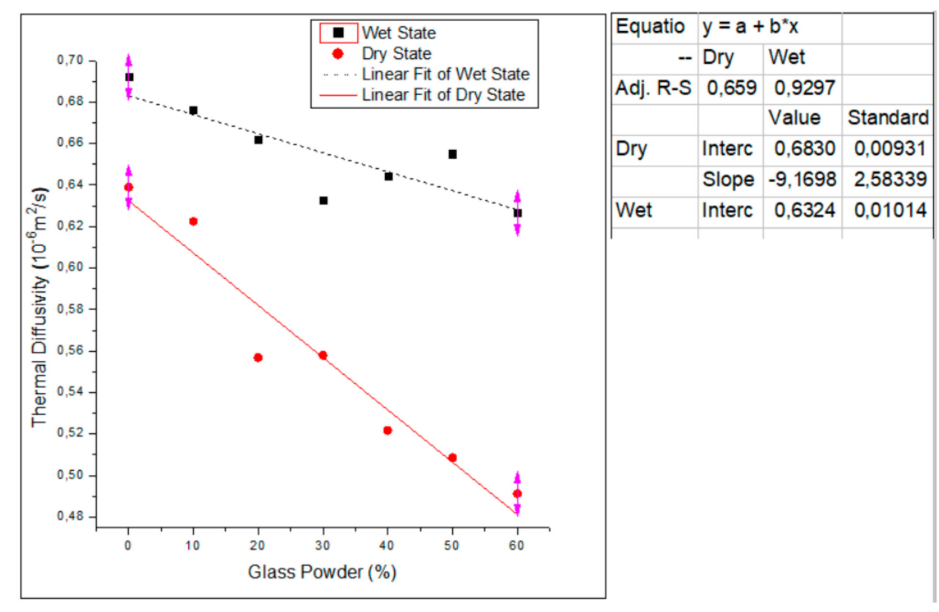

Figure 9. Variation of the measured thermal diffusivity at dry and wet states as a function of the glass powder content.

The curve in Figure 9 shows that the thermal diffusivity decreases, in the dry state, from 0.63 to 0.49 , which corresponds to an average of $22.22 \%$. However, in the saturated state, this thermal diffusivity decreases from 0.69 to 0.64 , which corresponds to an average of $7.24 \%$. This new result is in full agreement with the previous results, in which we have shown a decrease in both thermal conductivity and density as a function of the glass powder content, which is also associated with a small decrease in specific heat. In the following sections, we will present the behavior of the thermal diffusivity of mortars with the glass powder content.

\subsection{Influence of Temperature on Thermal Conductivity and Specific Heat}

Temperature is a factor that influences the thermal properties of concrete and mortar. The study of the thermal properties of glass-based mortars, at high temperatures, has been the subject of this research study [20]. Until now, the study of the thermal properties of substituted mortars with a high content of glass powder as a function of temperature, while very important, has not yet been carried out. For this, we present here a detailed study of the influence of temperature on the thermal properties of mortars based on glass with different contents $(10 \%, 20 \%, 30 \%, 40 \%, 50 \%$ and $60 \%)$. The thermal properties of carefully prepared mortars were measured in the dry state, in a temperature range between 20 and $50{ }^{\circ} \mathrm{C}$, using the $\mathrm{CT}$ meter instrument equipped with a temperature regulator. The results 
obtained, presented in Figure 10a, show that the thermal conductivity undergoes a strong decrease if the rate of substitution in glass powders increases. This tendency remains valid for all the temperatures studied (between 20 and $50{ }^{\circ} \mathrm{C}$ ). However, these results also show, as expected, a decrease in thermal conductivity if the temperature decreases. The thermal conductivity goes from 1.11 to $0.86 \mathrm{~W} /(\mathrm{mK})$ for the mortar at $60 \%$ glass powder when the temperature is set at $20^{\circ} \mathrm{C}$. There is also a remarkable slowdown in the rate of growth of thermal conductivity above $40^{\circ} \mathrm{C}$. The linear tendencies of the thermal conductivity curves proves that it is possible to establish a simple empirical law allowing expression of the variation of thermal conductivity as a function of the temperature and the glass powder content.

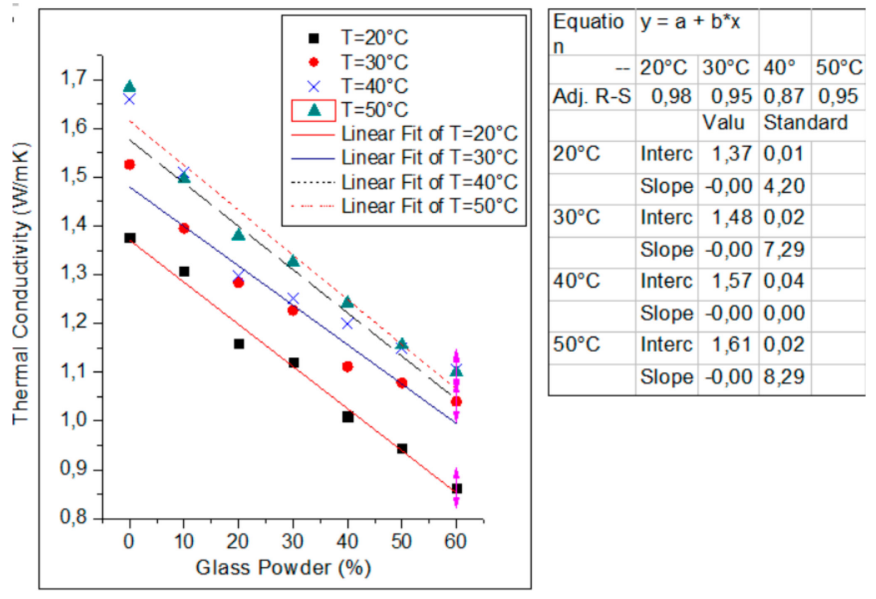

(a)

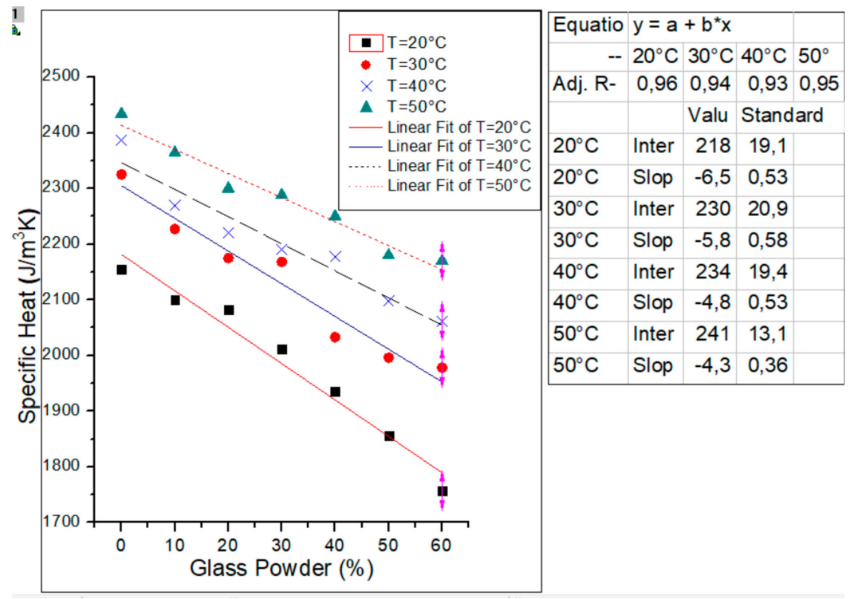

(b)

Figure 10. Variation of the measured thermal conductivity (a) and specific heat (b) with the glass powder content at different temperature (\%GP).

It is interesting to note that the samples are composed of solid (mineral), liquid (water), and gas (air) phases. The thermal conductivity of several minerals (amorphous quartz, etc.), which make up the mortar, increases with temperature. Even if the samples have been oven-dried, there may still be water or gas trapped in the pores. However, the thermal conductivity values of air and water in the temperature range $\left(20-50{ }^{\circ} \mathrm{C}\right)$ are respectively $(0.026-0.028 \mathrm{~W} /(\mathrm{mK}))$ and $(0.59-0.64 \mathrm{~W} /(\mathrm{mK}))$. These observations may partly explain the remarkable slowing down of the growth rate of thermal conductivity above $40{ }^{\circ} \mathrm{C}$, illustrated in Figure 10a. This result can also be explained in part by the fact that an increase in temperature causes an expansion of the grains and, therefore, a decrease in porosity. Thus, the heat flow then passes through the particles of glass, sand, and cement. Figure 10a clearly shows that at a fixed temperature, the thermal conductivity of mortars decreases if the percentage of glass powder substitution increases. This is due to the fact that glass powder, having a thermal conductivity of $0.18 \mathrm{~W} /(\mathrm{mK})$, constitutes a good thermal insulator. Specific heat is a thermodynamic variable, which varies as a function of temperature. The results presented in Figure 10b show that the specific heat increases if the temperature increases and/or the substitution rate decreases. The specific heat of the control mortar increases from 2155 to $2434 \mathrm{KJ} / \mathrm{m}^{3} \mathrm{~K}$, and the mortar with a high glass powder content $(60 \%)$ increases from 1757 to $2170 \mathrm{KJ} / \mathrm{m}^{3} \mathrm{~K}$ between 20 and $50{ }^{\circ} \mathrm{C}$. The specific heat of the different types of light aggregate concrete studied decreases to a minimum value when the temperature is between 5 and $20^{\circ} \mathrm{C}$, then increases with increasing temperature at $50^{\circ} \mathrm{C}$, which is similar to the results obtained for mortars with different substitutions of glass powder. 


\section{Conclusions}

The aim of this study is to evaluate the influence of soda-lime glass waste, as a cement substitute, on the thermophysical properties of cement mortar.

The following major conclusions can be drawn:

- The incorporation of waste glass powder contents into the cement mortar reduced the thermophysical properties' values by 37,18 and $22 \%$ respectively for thermal conductivity, volumetric specific heat and thermal diffusivity. In a dry state, the increase in the substitution rate of the glass powder leads to an increase in the volume of the pores, which causes a lower density and consequently, the thermal conductivity and volumetric specific heat of the mortars decreases. This could be explained by the low absorption of water in the glass. In a saturated state, the increase in the volumic mass of the samples could be explained by water occupating the empty pores, which subsequently induces the increase of the density of the mortars.

- According to SEM results, the chemical composition of the glass powder makes this material competitive as a pozzolanic material. The glass powder addition decreases the portlandite quantity and develops C-S-H gels. The use of glass powder in the mortar leads to modifications of the pore size.

- The density of the new mortar was also reduced by approximately $11 \%$ in the dry state and $5 \%$ in the wet state. This decrease in density, dry and/or wet, has a significant effect on the thermo-physical parameters of this composite compared to the reference mortar.

- Incorporation glass powder also reduces the specific heat for the two hydric states discussed (dry and saturated). This can be explained by the low specific thermal value of the glass $\left(913 \mathrm{KJ} / \mathrm{m}^{3} \mathrm{~K}\right)$, which is located in pores.

- The thermal conductivity increases when the temperature increases and/or the substitution rate decreases. Thus, at $60 \%$ glass powder, the thermal conductivity increases by $22.25 \%$ when the temperature varies from $20^{\circ} \mathrm{C}$ to $50^{\circ} \mathrm{C}$. This result can be explained in part by the fact that an increase in temperature causes an expansion of the grains and, therefore, a decrease in porosity.

Author Contributions: The following statements should be used "Conceptualization, O.N. and A.S.; methodology, A.H.-A.; software, O.N. and H.S.E.I.; validation, A.S.; formal analysis, H.S and A.M.; investigation, A.S.; resources S.E.D.F. and S.B.; data curation, H.S.; Y.E.R.; writing-original draft preparation, O.N.; writing — review and editing, O.N.; visualization, M.H., project administration, A.H.-A. All authors have read and agreed to the published version of the manuscript.

Funding: This research received no external funding.

Institutional Review Board Statement: Not applicable.

Informed Consent Statement: Not applicable.

Data Availability Statement: The data presented in this study are available on request from the corresponding author.

Acknowledgments: The authors would like to thank the UATRS-CNRST for the scanning electron microscopy performed for the tests.

Conflicts of Interest: The authors declare no conflict of interest.

\section{References}

1. Malik, M.; Bhattacharyya, S.; Barai, S.V. Thermal and mechanical properties of concrete and its constituents at elevated temperatures: A review. Constr. Build. Mater. 2021, 270, 121398. [CrossRef]

2. Asadi, I.; Shafigh, P.; Hashemi, M.; Akhiani, A.R.; Maghfouri, M.; Sajadi, B.; Mahyuddin, N.; Esfandiari, M.; Talebi, H.R.; Metselaar, H.S.C. Thermophysical properties of sustainable cement mortar containing oil palm boiler clinker (OPBC) as a fine aggregate. Constr. Build. Mater. 2021, 268, 121091. [CrossRef]

3. Oren, O.H.; Gholampour, A.; Gencel, O.; Ozbakkaloglu, T. Physical and mechanical properties of foam concretes containing granulated blast furnace slag as fine aggregate. Constr. Build. Mater. 2020, 238, 117774. [CrossRef]

4. Tekin, I.; Gencel, O.; Gholampour, A.; Oren, O.H.; Koksal, F.; Ozbakkaloglu, T. Recycling zeolitic tuff and marble waste in the production of eco-friendly geopolymer concretes. J. Clean. Prod. 2020, 268, 122298. [CrossRef] 
5. Belouadah, M.; Rahmouni, Z.E.A.; Tebbal, N. Influence of the addition of glass powder and marble powder on the physical and mechanical behavior of composite cement. Procedia Comput. Sci. 2019, 158, 366-375. [CrossRef]

6. Mohammadyan-Yasouj, S.E.; Ghaderi, A. Experimental investigation of waste glass powder, basalt fibre, and carbon nanotube on the mechanical properties of concrete. Constr. Build. Mater. 2020, 252, 119115. [CrossRef]

7. Hwang, S.S.; Cortés, C.M.M. Properties of mortar and pervious concrete with co-utilization of coal fly ash and waste glass powder as partial cement replacements. Constr. Build. Mater. 2021, 270, 121415. [CrossRef]

8. Jani, Y.; Hogland, W. Waste glass in the production of cement and concrete-A review. J. Environ. Chem. Eng. 2014, 2, 1767-1775. [CrossRef]

9. Kamali, M.; Ghahremaninezhad, A. Effect of glass powders on the mechanical and durability properties of cementitious materials. Constr. Build. Mater. 2015, 98, 407-416. [CrossRef]

10. Nahi, S.; Leklou, N.; Khelidj, A.; Oudjit, M.N.; Zenati, A. Properties of cement pastes and mortars containing recycled green glass powder. Constr. Build. Mater. 2020, 262, 120875. [CrossRef]

11. Elaqra, H.; Rustom, R. Effect of using glass powder as cement replacement on rheological and mechanical properties of cement paste. Constr. Build. Mater. 2018, 179, 326-335. [CrossRef]

12. Du, H.; Tan, K.H. Properties of high volume glass powder concrete. Cem. Concr. Compos. 2017, 75, 22-29. [CrossRef]

13. Somé, S.C.; Ben Fraj, A.; Pavoine, A.; Chehade, M.H. Modeling and experimental characterization of effective transverse thermal properties of hemp insulation concrete. Constr. Build. Mater. 2018, 189, 384-396. [CrossRef]

14. Mohajerani, A.; Vajna, J.; Cheung, T.H.H.; Kurmus, H.; Arulrajah, A.; Horpibulsuk, S. Practical recycling applications of crushed waste glass in construction materials: A review. Constr. Build. Mater. 2017, 156, 443-467. [CrossRef]

15. Lu, J.-X.; Zhan, B.-J.; Duan, Z.-H.; Poon, C.S. Using glass powder to improve the durability of architectural mortar prepared with glass aggregates. Mater. Des. 2017, 135, 102-111. [CrossRef]

16. Kalakada, Z.; Doh, J.; Zi, G. Utilisation of coarse glass powder as pozzolanic cement-A mix design investigation. Constr. Build. Mater. 2020, 240, 117916. [CrossRef]

17. Jiang, Y.; Ling, T.-C.; Mo, K.H.; Shi, C. A critical review of waste glass powder-Multiple roles of utilization in cement-based materials and construction products. J. Environ. Manag. 2019, 242, 440-449. [CrossRef] [PubMed]

18. Ez-Zaki, H.; El Gharbi, B.; Diouri, A. Development of eco-friendly mortars incorporating glass and shell powders. Constr. Build. Mater. 2018, 159, 198-204. [CrossRef]

19. Islam, G.S.; Rahman, M.; Kazi, N. Waste glass powder as partial replacement of cement for sustainable concrete practice. Int. J. Sustain. Built Environ. 2017, 6, 37-44. [CrossRef]

20. Pan, Z.; Tao, Z.; Murphy, T.; Wuhrer, R. High temperature performance of mortars containing fine glass powders. J. Clean. Prod. 2017, 162, 16-26. [CrossRef]

21. Zheng, K. Pozzolanic reaction of glass powder and its role in controlling alkali-silica reaction. Cem. Concr. Compos. 2016, 67, 30-38. [CrossRef]

22. Matos, A.M.; Sousa-Coutinho, J. Waste glass powder in cement: Macro and micro scale study. Adv. Cem. Res. 2016, 28, 1-10. [CrossRef]

23. Shafaatian, S.M.H.; Wright, J.R.; Rajabipour, F. Performance of recycled soda-lime glass powder in mitigating alkali-silica reaction. Green Mater. 2019, 7, 28-39. [CrossRef]

24. Bignozzi, M.; Saccani, A.; Barbieri, L.; Lancellotti, I. Glass waste as supplementary cementing materials: The effects of glass chemical composition. Cem. Concr. Compos. 2015, 55, 45-52. [CrossRef]

25. Omran, A.; Soliman, N.; Zidol, A.; Tagnit-Hamou, A. Performance of Ground-Glass Pozzolan as a Cementitious Material—A Review. Adv. Civ. Eng. Mater. 2018, 7, 237-270. [CrossRef]

26. Sinha, D.D.A. Thermal properties of concrete. PARIPEX-Indian J. Res. 2014, 3, 90-91. [CrossRef]

27. Nguyen, L.; Beaucour, A.-L.; Ortola, S.; Noumowé, A. Experimental study on the thermal properties of lightweight aggregate concretes at different moisture contents and ambient temperatures. Constr. Build. Mater. 2017, 151, 720-731. [CrossRef]

28. Zhang, Y.; Sun, Q.; Yang, X. Changes in color and thermal properties of fly ash cement mortar after heat treatment. Constr. Build. Mater. 2018, 165, 72-81. [CrossRef]

29. Liu, S.; Xie, G.; Wang, S. Effect of glass powder on microstructure of cement pastes. Adv. Cem. Res. 2015, 27, 259-267. [CrossRef]

30. Zhang, L.; Gustavsen, A.; Jelle, B.P.; Yang, L.; Gao, T.; Wang, Y. Thermal conductivity of cement stabilized earth blocks. Constr. Build. Mater. 2017, 151, 504-511. [CrossRef]

31. Sikora, P.; Horszczaruk, E.; Skoczylas, K.; Rucinska, T. Thermal Properties of Cement Mortars Containing Waste Glass Aggregate and Nanosilica. Procedia Eng. 2017, 196, 159-166. [CrossRef] 